(de Pedro Vélez de Guevara); 335 (de Gonzalo Martínez de Medina); 348 (de Frey Lope de Monte); y 547 (de Fernán Pérez de Guzmán). Por eso sigo creyendo que Imperial, al escribir el Decir de las siete virtudes, se preocupaba mucho más por el estado, reconocidamente malo, de su ciudad adoptiva y por la aplicación de remedios fuertes, que por "las vagas condenas de todos los tradicionales enemigos de la fe cristiana" (palabras de la Srta. Lida, op. cit., pág. 175).

Sin embargo, reconozco que la Srta. Lida tiene razón en poner en duda mi conjetura acerca de la "good impression [hecha por la manifestación de antisemitismo de parte de Imperial] on the educated contemporaries of Imperial (including Santillana's poet uncles...)", y por falta de pruebas retiro esta conjetura.

En conclusión, quisiera aprovecharme de esta ocasión para corregir la impresión corriente entre varios críticos españoles de que yo procurara, con mi artículo titulado The Exaggerated Reputation of Francisco Imperial, deprimir el ingenio poético de Imperial. Nada más lejos de la verdad. Mi artículo trata de un problema de historia literaria y de ninguna manera se ocupa con cuestiones de crítica literaria. Para mí, Francisco Imperial sigue siendo lo que siempre fué: un poeta de gran talento y a veces de verdadera inspiración poética - de hecho la voz más lírica de su época.

EDWIN B. PLACE

Northwestern University

\title{
SOBRE LA DIFUSIÓN DE LA LEYENDA DEL PURGATORIO DE SAN PATRICIO EN ESPAÑA
}

Acerca de la tradición del purgatorio de San Patricio en España, creencia de origen extranjero, ha recogido todo lo conocido Antonio G. Solalinde, La primera versión española de "El purgatorio de San Patricio" y la difusión de esta leyenda en España, artículo inserto en el Homenaje a Menéndez Pidal, Madrid, 1925, II, págs. 219-257. Con posterioridad apareció la obra de C. M. van den Zanden, Etude sur le Purgatoire de Saint Patrice, Amsterdam, 1927, que poco o nada agrega acerca de la difusión en España. No he podido ver el artículo de P. Mac Bride, St. Patrick's Purgatory in Spanish literature, Studies in Irish Quarterly, 1936, xxv. Solalinde recoge únicamente los títulos de dos comedias en las cuales se utilice esta leyenda: El mayor prodigio y el purgatorio en la vida, atribuída a Lope de Vega ${ }^{1}$, y El purgatorio de San Patricio de Calderón de la Barca. La fuente de ambas comedias fué la obra del Dr. Juan Pérez de Montalván, Vida y purgatorio del glorioso San Patricio, arzobispo y primado de Hibernia, escrita por el doctor..., Madrid, $1627^{2}$.

Revisando el voluminoso Cancionero de 1628 editado por José Manuel Blecua ${ }^{3}$ encontramos la composición número 412 (pág. 490) cuyo epígrafe dice A María de Córdoba, en la comedia de San Patricio. Blecua supone (pág. 54) que esa comedia sería la de Calderón y por consiguiente quiere retrotraer la fecha de su composición hasta el año 1628. Conviene sutilizar un poco la investigación para evitar un error que podría tener consecuencias en la cronología calderoniana.

1 S. G. Morley y C. Bruerton (por no citar más que un estudio reciente), The chronology of Lope de Vega's comedias, New York, 1940, pág. 310, se inclinan a dudar de su autenticidad. Para ellos, "la obra, al menos en su forma presente, no es de Lope".

2 La novela de don Alonso de Castillo Solórzano, Tiempo de regocijo y carnestolendas de Madrid, Madrid, 1627, se halla precedida por unas palabras Al bien intencionado que suscribe el propio Montalván, quien anuncia la próxima publicación de su tratado acerca del purgatorio de San Patricio. (Cf. Colección selecta de antiguas novelas españolas, vir, Madrid, 1907, pág. 190).

3 Madrid, 1945, anejo xxxir de la RFE. Hace tiempo que la lírica peninsular no recibía un aporte de nuevos materiales de la importancia del presente Cancionero. El único inconveniente que presenta para su manejo es la defectuosa confección de los índices. 
Acerca de la relación entre la comedia atribuída a Lope y la de Calderón, la mayoría de los eruditos están contestes en admitir la influencia de la primera sobre la segunda. Se pueden citar los nombres de los siguientes estudiosos: Léo Rouanet, Drames réligieux de Calderón, Paris, 1898, pág. 289; Menéndez Pelayo, Observaciones preliminares al tomo $\mathrm{v}$ de las Obras de Lope de Vega, pág. LvII, y A. G. Solalinde, art. cit. pág. 256. Opinión distinta fué la de A. Schaeffer, Geschichte des spanischen Nationaldramas, Leipzig, 1890, I, 203, pero a pesar de su indiscutible autoridad considero más valederas las razones aducidas por el bando contrario.

Con referencia a la fecha de composición de la comedia atribuída a Lope, que lógicamente tiene que ser la primera, me remito a Rouanet, ob. cit., pág. 287, quien trató ampliamente de la cuestión. Tomando como base el nombre de Avendaño que aparece en el manuscrito de la comedia (dice: El mayor prodigio, comedia famosa de Lope de Vega Carpio. Representóla Avendaño), el estudioso francés razona de la siguiente manera: "Le nom d'Avendaño nous permet d'assigner à l'oeuvre une date approximative. Il ne peut être question ici que de Cristóbal de Avendaño el mozo, lequel mourut en 1635. La comedia de Lope fut donc représentée forcément entre l'année 1627, où parut le livre de Montalván qui lui servit de modèle, et l'année 1635 où mourut son principal interprète".

El purgatorio de San Patricio de Calderón fué impreso en la Primera parte de comedias de D..., Madrid, 1636. Cotarelo y Mori, en su Ensayo sobre la vida y obras de don Pedro Calderón de la Barca, no dice nada acerca de la posible fecha de composición de esta comedia. Tampoco lo hace Menéndez Pelayo en su libro sobre Calderón y su teatro. Harry Warren Hilborn, A chronology of the plays of D. Pedro Calderón de la Barca, Toronto, 1938, conjetura que la fecha sería la de 1634. La opinión de Blecua ya queda indicada.

La fecha de 1628 que ostenta el Cancionero editado por Blecua es indiscutible, como éste prueba en las págs. 8-10. Luego las composiciones en él recopiladas tienen que ser de fecha anterior, lo que hace muy dudosa la probabilidad de que el epígrafe de la poesía en cuestión se pueda referir a la comdia atribuída a Lope, y más dudosa aún la alusión a Calderón. Para explicar esta dificultad, no creo que sea necesario acudir a los extremos a que apela Blecua, retrotrayendo en más de seis años la fecha de composición de la comedia de Calderón. Hay otra solución: la existencia de una comedia desconocida acerca del tema del purgatorio de San Patricio. Las fuentes de esta comedia no creo que ofrezcan gran dificultad. No pudiendo ser su modelo la obra de Pérez de Montalván, basta remontarse un poco para encontrar la famosa narración de Ramón, vizconde de Perellós y de Rodas, que se puede reconstruir gracias a un manuscrito languedociano de 1466, un incunable catalán de 1486, un manuscrito castellano de principios del siglo xvir y una traducción latina hecha en 1621 por Felipe O'Sullivan (cf. Soldalinde, art. cit., págs. 252-253). Cualquiera de las dos últimas versiones pudo haber sido la fuente de nuestra desconocida comedia.

Que la comedia citada en el epígrafe no es la de Lope queda demostrado con este otro hecho: María de Córdoba, la bella Amarilis para sus partidarios, y la gran Sultana para sus enemigos, no actuó nunca en la compañía de Cristóbal de Avendaño (véase el excelente estudio de Narciso Díaz de Escovar, Comediantes de otros siglos. La bella Amarilis, BAH, 1931, xcvirr, págs. 323-362).

Hay que rechazar, pues, la afirmación de Blecua, quien supone que la mencionada comedia sería la de Calderón, lo que va en contra de toda la cronología aquí establecida, a menos que se acepte - y no hay razón alguna para hacerlo- que El purgatorio de San Patricio se escribió antes de 1628. 